\title{
Donor-derived stem-cells and epithelial mesenchymal transition in squamous cell carcinoma in transplant recipients
}

\author{
Laurence Verneuil'1,2,3,4, Christophe Leboeuf ${ }^{1,2}$, Guilhem Bousquet ${ }^{1,2}$, Charlotte \\ Brugiere $^{1,2,3,4}$, Morad Elbouchtaoui ${ }^{1,2,5}$, Louis-François Plassa ${ }^{2}$, Marie-Noelle \\ Peraldi $^{2,6}$, Celeste Lebbé ${ }^{2,7}$, Philippe Ratajczak ${ }^{1,2}$ and Anne Janin ${ }^{1,2,5}$ \\ 1 INSERM, UMR_S1165, Paris, F-75010, France \\ 2 Department of Pathology, Université Paris Diderot, UMR_S1165, F-75010 Paris, France \\ 3 Department of Dermatology, CHU Caen, Caen, F-14033, France \\ ${ }^{4}$ Université de Caen Normandie, Medical School, Caen, F-14000, France \\ ${ }^{5}$ Department of Pathology, AP-HP, Hôpital Saint-Louis, Paris, F-75010, France \\ ${ }^{6}$ Department of Nephrology, AP-HP, Hôpital Saint-Louis, Paris, F-75010, France \\ 7 Department of Dermatology, AP-HP, Hôpital Saint-Louis, Paris, F-75010, France \\ Correspondence to: Anne Janin, email: anne.janin1165@gmail.com
}

Laurence Verneuil, email: laurence.vernevil@gmail.com

Keywords: squamous cell carcinoma, stem-cell, epithelial mesenchymal transition, kidney transplant, chimerism, Pathology Section

Received: May 17, $2015 \quad$ Accepted: November 16, $2015 \quad$ Published: November 22, 2015

\section{ABSTRACT}

\section{Background}

Skin squamous-cell-carcinoma (SCC), is the main complication in long-term kidney-transplant recipients, and it can include donor-derived cells. Preclinical models demonstrated the involvement of epithelial mesenchymal transition (EMT) in the progression of skin SCC, and the role of Snail, an EMT transcription factor, in cancer stem-cell survival and expansion.

Here, we studied stem-cells and EMT expression in SCCs and concomitant actinic keratoses (AK) in kidney-transplant recipients.

Methods

In SCC and AK in 3 female recipients of male kidney-transplants, donor-derived $Y$ chromosome in epidermal stem cells was assessed using combined XY-FISH/CD133 immunostaining, and digital-droplet-PCR on laser-microdissected CD133 expressing epidermal cells.

For EMT study, double immunostainings of CD133 with vimentin or snail and slug, electron microscopy and immunostainings of keratinocytes junctions were performed. Digital droplet PCR was used to check CDH1 (E-cadherin) expression level in lasermicrodissected cells co-expressing CD133 and vimentin or snail and slug.

The numbers of Y-chromosome were assessed using digital droplet PCR in lasermicrodissected cells co-expressing CD133 and vimentin, or snail and slug, and in CD133 positive cells not expressing any EMT maker.

Results

We identified donor-derived stem-cells in basal layers and invasive areas in all skin SCCs and in concomitant AKs, but not in surrounding normal skin.

The donor-derived stem-cells expressed the EMT markers, vimentin, snail and slug in SCCs but not in AKs. The expression of the EMT transcription factor, SNAI1, was higher in stem-cells when they expressed vimentin. They were located in invasive 


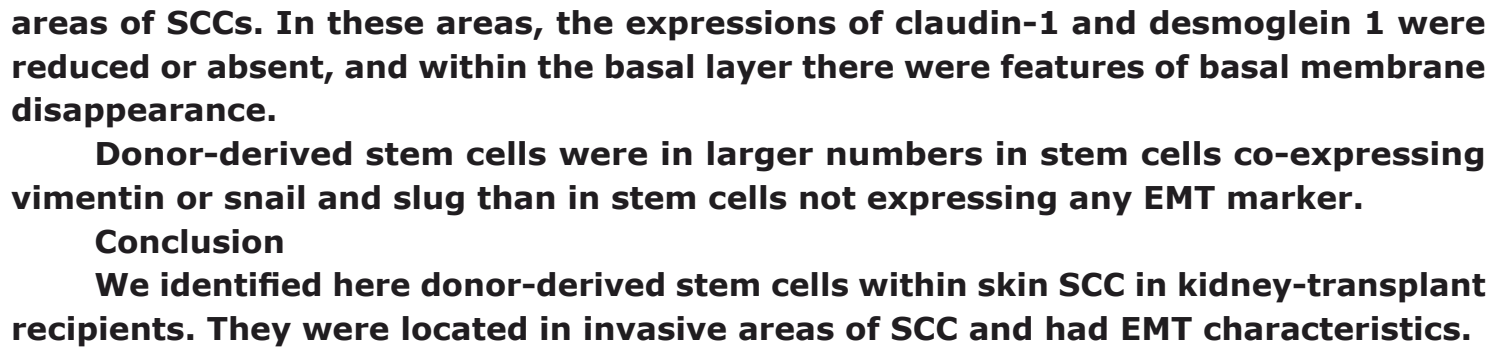

\section{INTRODUCTION}

Cancer, particularly skin squamous-cell carcinoma (SCC), is the main complication in long-term transplanted patients [1]. Preclinical models demonstrated the involvement of epithelial mesenchymal transition (EMT) in the progression of skin SCC [2], and the role of Snail, an EMT transcription factor, in cancer stem-cell survival and expansion [3].

In kidney-transplant recipients, we recently identified donor-derived epithelial cells in skin SCC and actinic keratosis (AK) [4], but the type of donor cell that homed to the skin remained to be characterized.

Here, we focused on donor-derived cells in skin SCC and AK to address the questions of stem-cell identification and EMT marker expression.

\section{RESULTS}

\section{Donor-derived cells in SCC and AK expressed CD133}

XY-FISH analyses performed in four female recipients of male kidney transplants, without earlier male pregnancies, showed keratinocytes with donor genotype in SCC and AK in Patients 1,2, and 3 (Table 1), and recipient genotype in Patient 4.

Donor-derived XY cells (Figure 1) were distributed in the epidermal basal layers and invasive areas in the three SCC, and in the epidermal basal layers in the three AK. In 100 keratinocytes counted in each sample, the mean percentage of donor-derived $\mathrm{XY}$ cells was significantly higher in the three SCC $(7.9 \%)$ than in the three AK (2.5\%), ( $\mathrm{p}<0.05)$ (Table 1). No donor-derived cell was found in non-tumoral tissue surrounding the SCCs.

When we assessed the expression of CD133, a marker for stem-cells, we found that CD133-expressing cells were also distributed in the epidermal basal layers in AK and in the proliferating outer cell layers in SCC. In 100 keratinocytes counted in each sample, we found a significantly higher mean percentage of CD133-expressing cells in SCC $(1.8 \%)$ than in AK $(0.3 \%)(\mathrm{p}<0.05)$.

To further study if some CD133-expressing cells were donor-derived, we used i) combined CD133 and XYFISH (Figure 1D), and ii) laser-microdissection of CD133expressing cells (Supplementary Figure 1) followed by Y-chromosome detection using droplet-digital-PCR (ddPCR). These two independent methods identified donor-derived CD133-expressing cells in SCC and AK. ddPCR quantification showed that the mean percentage of Y-chromosome in CD133 laser-microdissected cells was significantly higher in SCC (9.8\%) than in AK (4.8\%) $(\mathrm{p}<0.05)$.

Taken together, these results demonstrated that donor-derived CD133-expressing stem-cells were present in SCCs and AKs in three kidney-transplant recipients.

\section{Donor-derived stem-cells expressing EMT markers were found in SCCs but not in AK}

The presence of donor-derived CD133 expressing cells in invasive areas of SCC led us to study if they expressed markers of proliferation and/or invasion.

Double immunofluorescence of CD133 and Ki67 showed that CD133 expressing were located in invasive areas of SCC with numerous Ki67 expressing cells (Figure $2 \mathrm{~A}$ ), but we did not find cells co-expressing CD133 and $\mathrm{Ki} 67$ in these areas.

Since EMT is an important driver in cancer invasion, we studied the expression of vimentin and snail/slug in invasive areas of SCC.

Vimentin expressing cells were found in invasive areas of SCC (Figure 2B) and some of these cells coexpressed CD133 (Figure 2C). Counts performed in these areas showed that $11.4 \%, 8.9 \%$, and $6.8 \%$ of $\mathrm{CD} 133$ cells co-expressed vimentin in Patients 1, 2, and 3 respectively (mean $=9.0 \%$ ). When we laser-microdissected cells only expressing CD133, and cells co-expressing CD133 and vimentin, we found a lower expression of $\mathrm{CDH} 1$ (E-cadherin) (Figure 2D) and a higher expression of SNAI1 (Figure 2E) in cells co-expressing CD133 and vimentin than in cells only expressing CD133.

In the three AK studied, no cell co-expressing CD133 and vimentin was found (Supplementary Figure 2).

Snail/slug expressing cells were numerous in basal layer and invasive areas of SCC (Figure 2F) and some of them co-expressed CD133 (Figure 2G). Counts performed in these areas showed that $10.4 \%, 7.5 \%$, and $5.6 \%$ of CD133 cells co-expressed snail/slug in Patients 1, 2, and 
Table 1: XY-FISH data in AK and SCC in three female recipients of male kidney transplants

\begin{tabular}{|c|c|c|c|c|c|c|c|c|}
\hline \multirow{3}{*}{\multicolumn{2}{|c|}{$\begin{array}{c}\text { Sex } \\
\begin{array}{c}\text { Recipient } \\
\text { / Donor }\end{array}\end{array}$}} & \multicolumn{2}{|c|}{ Kidney transplantation } & \multicolumn{2}{|c|}{ Skin tumors } & \multicolumn{3}{|c|}{ XY FISH } \\
\hline & & \multirow{2}{*}{$\begin{array}{c}\text { Age at } \\
\text { transplant } \\
\text { (years) }\end{array}$} & \multirow{2}{*}{$\begin{array}{c}\text { Time lapse } \\
\text { transplant- } \\
\text { tumor (years) }\end{array}$} & \multirow{2}{*}{ Site } & \multirow{2}{*}{ Type } & \multicolumn{3}{|c|}{ Keratinocytes from basal layers and invasive areas } \\
\hline & & & & & & $\begin{array}{c}\text { XX cells } \\
\%\end{array}$ & $\begin{array}{c}\text { XY cells } \\
\%\end{array}$ & $\%$ Chimeric cells corrected* \\
\hline \multicolumn{8}{|c|}{ Skin tumors in female recipients of male kidney-transplants } & $\mathrm{XY}$ cells \\
\hline \multirow{2}{*}{1} & \multirow{2}{*}{$\mathrm{F} / \mathrm{M}$} & \multirow{2}{*}{43} & 12 & leg & $\mathrm{SCC}$ & 53.5 & 5.3 & 8.3 \\
\hline & & & 12 & cheek & $\mathrm{AK}$ & 65.7 & 2.0 & 2.7 \\
\hline \multirow{2}{*}{2} & \multirow{2}{*}{$\mathrm{F} / \mathrm{M}$} & \multirow{2}{*}{46} & 5 & arm & $\mathrm{SCC}$ & 61.7 & 3.9 & 6.2 \\
\hline & & & 5 & neck & AK & 65.3 & 2.4 & 3.3 \\
\hline \multirow{5}{*}{3} & \multirow{5}{*}{$\mathrm{F} / \mathrm{M}$} & \multirow{5}{*}{18} & 6 & arm & $\mathrm{SCC}$ & 54.9 & 5.9 & 9.3 \\
\hline & & & 6 & hand & $\mathrm{AK}$ & 67.0 & 1.1 & 1.5 \\
\hline & & & & & & & & mean XY cells for $\mathrm{SCC}=7.9$ \\
\hline & & & & & & & & mean $\mathrm{XY}$ cells for $\mathrm{AK}=2.5$ \\
\hline & & & & & & & & $p$ value $S C C$ vs $A K=0.05$ \\
\hline \multicolumn{9}{|c|}{ Skin tumors of a male recipient of a male kidney-transplant } \\
\hline \multirow{2}{*}{\multicolumn{2}{|c|}{$\mathrm{M} / \mathrm{M}$}} & \multirow{2}{*}{53} & 6 & nose & $\mathrm{SCC}$ & 0.0 & 54.5 & \\
\hline & & & 6 & cheek & $\mathrm{AK}$ & 0.0 & 58.7 & \\
\hline \multicolumn{9}{|c|}{ Skin tumors of male patients without kidney transplantation (control) } \\
\hline \multirow{2}{*}{\multicolumn{2}{|c|}{ M }} & & & nose & $\mathrm{SCC}$ & 0.0 & 66.1 & \\
\hline & & & & cheek & AK & 0.0 & 76.0 & \\
\hline \multirow{2}{*}{\multicolumn{2}{|c|}{ M }} & & & leg & $\mathrm{SCC}$ & 0.0 & 60.6 & \\
\hline & & & & leg & AK & 0.0 & 70.1 & \\
\hline
\end{tabular}

*Tumor samples from two males with SCC and AK without kidney transplantation (controls) were examined. To determine the efficiency of sex-chromosome detection in basal layers of SCC and AK, a FISH XY protocol was applied. Here the normalization factor was 1.37 and 1.58 for XX and XY cell detections of $\mathrm{AK}$ and SCC respectively. $(\mathrm{p}<0.05$, Khi-square test)

3 respectively (mean $=7,8 \%$ ).

To study if CD133/vimentin or CD133/snailslug co-expressing cells were donor-derived in the three SCCs studied, we laser-microdissected these cells and used ddPCR to detect the Y-chromosome. The percentage of Y-chromosome-bearing cells in CD133/ vimentin coexpressing cells was $69 \%, 54.5 \%$, and $49.5 \%$ for Patients 1, 2, and 3 respectively (mean 57. 7\%). These percentages were significantly different from the percentages of Y-chromosome-bearing cells in cells expressing CD133 but not vimentin in basal layer and invasive areas of SCC $(12 \%, 0 \%$, and $16 \%$ for Patients 1 , 2 , and 3 respectively, mean $9.3 \%$ ) (Figure $2 \mathrm{H}$ ).

Similarly the percentages of Y-chromosome-bearing cells in CD133/snail-slug co-expressing cells (65.5\%, $59 \%$, and $54 \%$ for Patients 1, 2, and 3 respectively, mean $59.5 \%$ ) was significantly higher than in cells expressing CD133 but not snail/slug in basal layers and invasive areas of the SCCs, $(10.5 \%, 0 \%$, and $18.5 \%$ for Patients 1,2 , and
3 respectively, mean 9.7\%) (Figure 2I).

Ultrastructural study focused on invasive areas of SCC. The systematic analysis of basal keratinocyte junctions showed a reduced number of zonula adherens and desmosomes, with partial disappearance of their dense components. On paraffin sections, immunoperoxydase staining of claudin-1 also showed a diminution of zonula adherens (Figure 3A), and immunostaining of desmoglein-1 showed a diminution of desmosomes (Figure 3B) in the same areas. For hemi-desmosomes and basal membrane, we found cells within the basal layer with scarce junctions and basal membrane disappearance, features in favour of a lessening of the epithelial characteristics (Figure 3C).

\section{DISCUSSION}

In skin SCC from kidney-transplant recipients, we identified donor-derived stem-cells in basal layer 


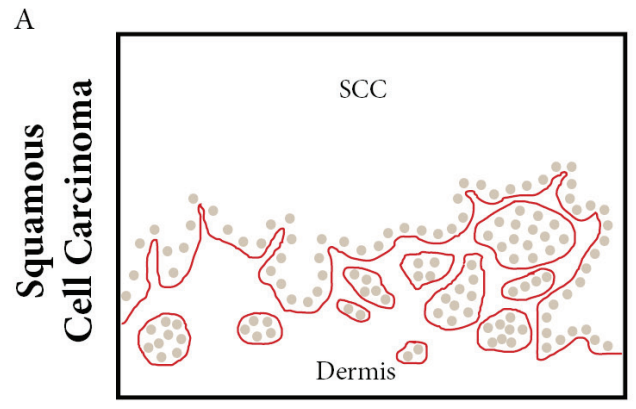

Ki67
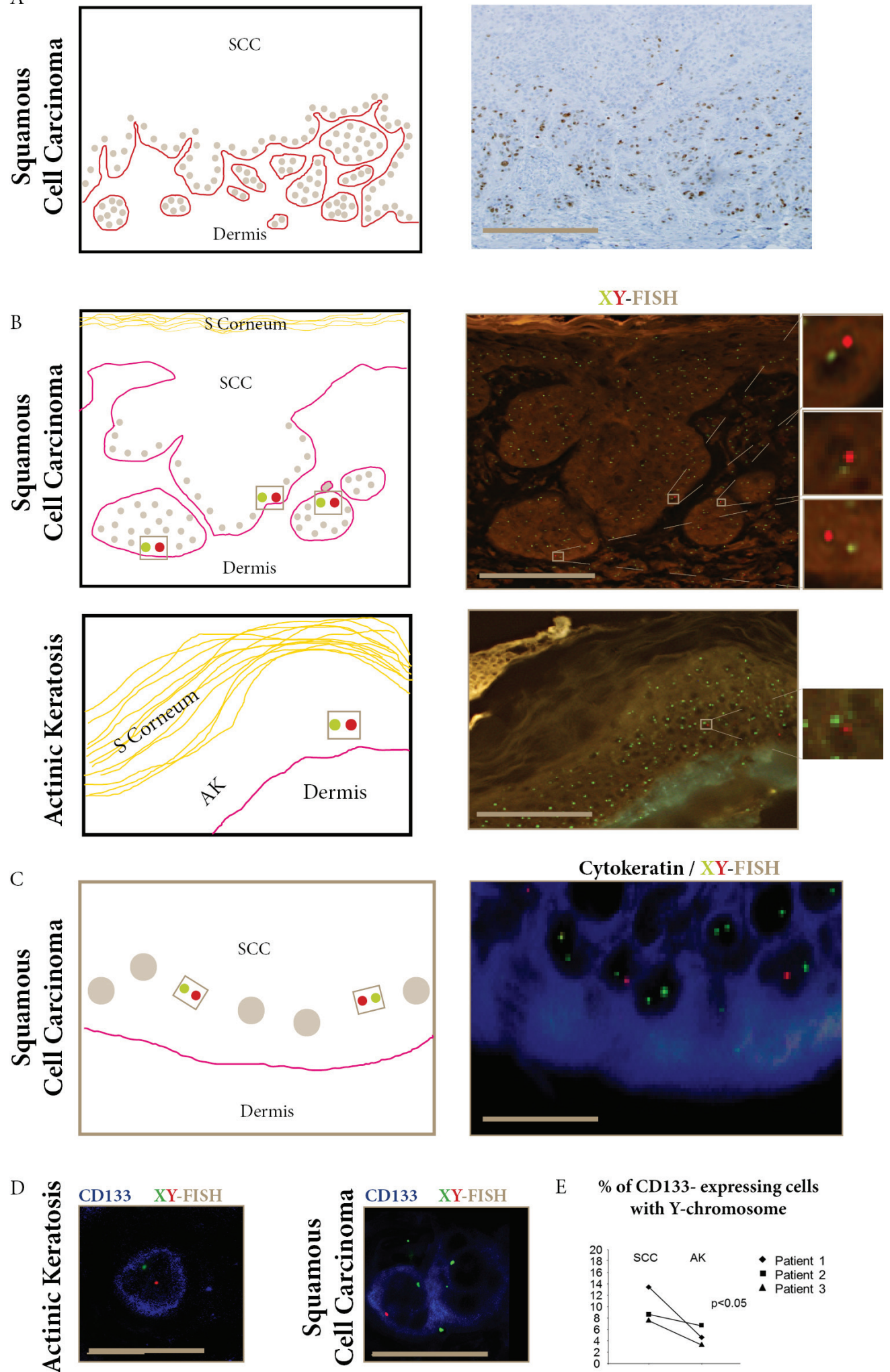

E \% of CD133- expressing cells with Y-chromosome

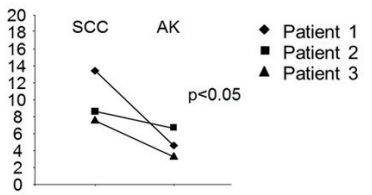

Figure 1: Donor- derived cells in SCC and AK express CD133. A. Ki67 staining of proliferative epidermal cells in the basal layer and invasive areas of SCC (bar $=100 \mu \mathrm{m})$. B. FISH-X (green) Y (red) show donor-derived XY cells in SCC invasive areas and AK epidermal basal layers (bars $=100 \mu \mathrm{m}$ ). C. Combined FISH-X (green) Y (red) and AE1/AE3 (blue) show donor-derived XY in cytokeratin-expressing cells in SCC basal layer (bar $=15 \mu \mathrm{m}$ ). D. Combined FISH-X (green) Y (red) and CD133 (blue) show donor-derived XY in CD133 expressing cells in AK and SCC (bar $=15 \mu \mathrm{m})$. E. The percentage of CD133-expressing cells with the Y-chromosome detected using droplet digital PCR is significantly higher in SCC than in AK in the three female recipients of male kidney-transplants. ( $\mathrm{p}<0.05$, Khi-square test). 

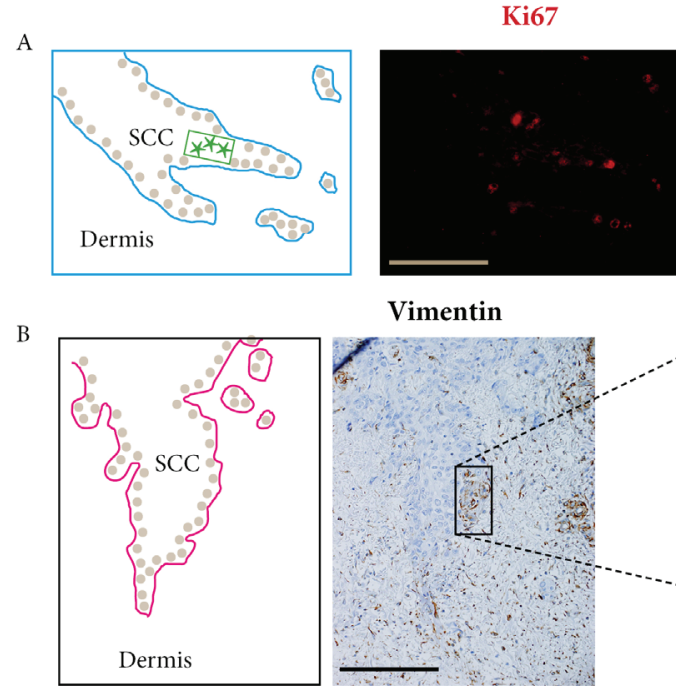

Vimentin

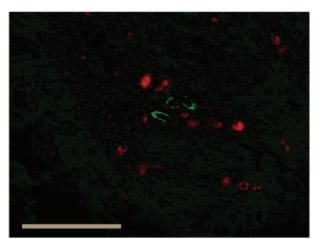

\section{Vimentin}
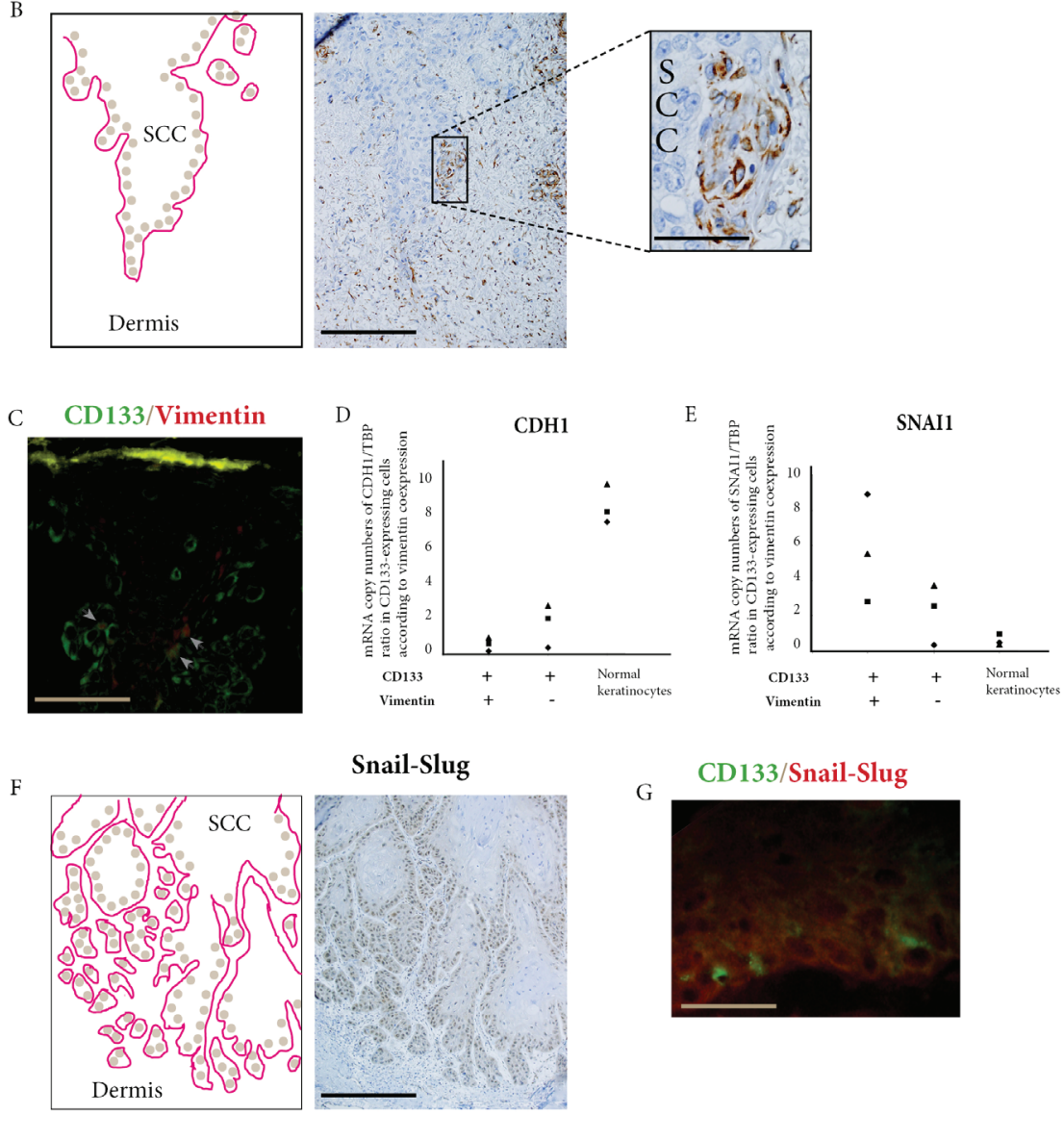

$\mathrm{H}$
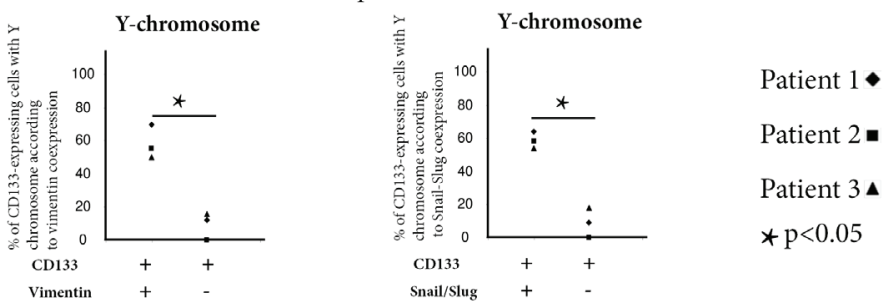

Figure 2: Donor-derived stem cells express EMT markers in squamous cell carcinoma. A. Combined CD133 (green) and Ki67 (red) immunofluorescent stainings show CD133 expressing cells in SCC invasive areas. These cells do not co-express Ki67 (bar $=100 \mu \mathrm{m})$. B. Immunoperoxydase staining of vimentin within cells of SCC basal layer (bar $=100 \mu \mathrm{m}$, higher magnification bar $=25 \mu \mathrm{m})$. C. Combined CD133 (green) and vimentin (red) immunofluorescence stainings show double positive cells (arrow heads) in SCC outer cell layers (bar $=25 \mu \mathrm{m})$. D. In SCCs of the three kidney-transplant recipients studied, CDH1 (E-cadherin) is under-expressed in cells coexpressing CD133 and vimentin compared with cells only expressing CD133, and with normal keratinocytes. E. In the same patients, SNAI1 (Snail1) is overexpressed in cells co-expressing CD133 and vimentin compared with cells only expressing CD133, and with normal keratinocytes. F. Immunoperoxydase staining of Snail-Slug within cells of SCC basal layer and invasive areas (bar $=150 \mu \mathrm{m})$. G. Combined CD133 (green) and Snail-Slug (red) immunofluorescent stainings show CD133 expressing cells in SCC outer cell layers. (bar=25 $\mu \mathrm{m})$. $\mathbf{H}$. In SCCs of the three kidney-transplant recipients studied, cells co-expressing CD133 and vimentin have more Y-chromosome detected by droplet digital PCR than cells only expressing CD133 ( $<<0.05$, Chi-square test). I. In SCCs of the three kidney-transplant recipients studied, cells co-expressing CD133 and Snail-Slug have more Y-chromosome detected by droplet digital PCR than cells only expressing CD133 $(\mathrm{p}<0.05$, Chi-square test $)$. 


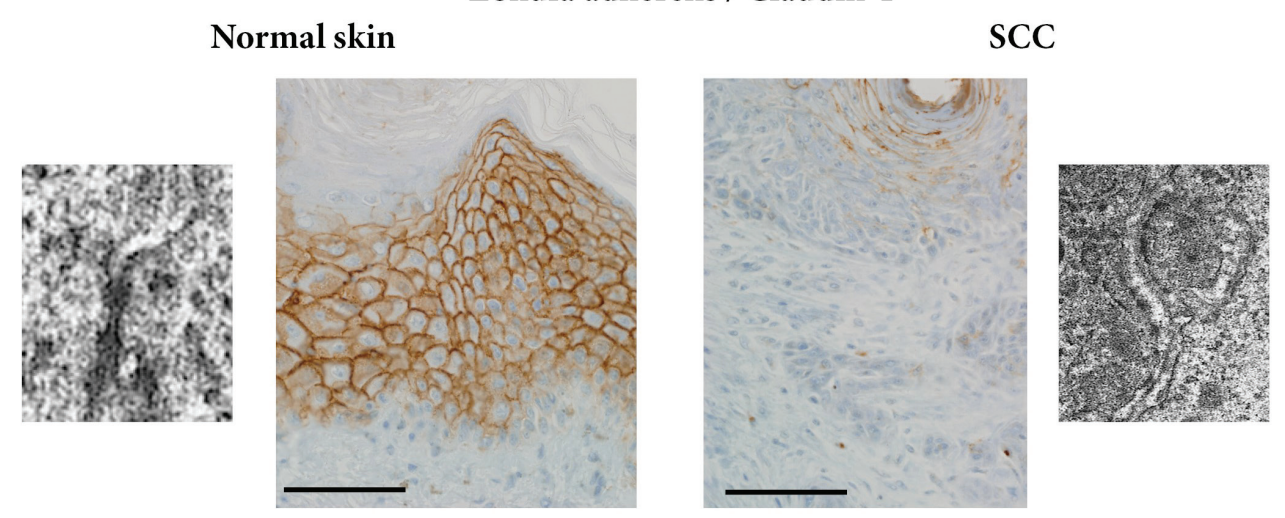

B

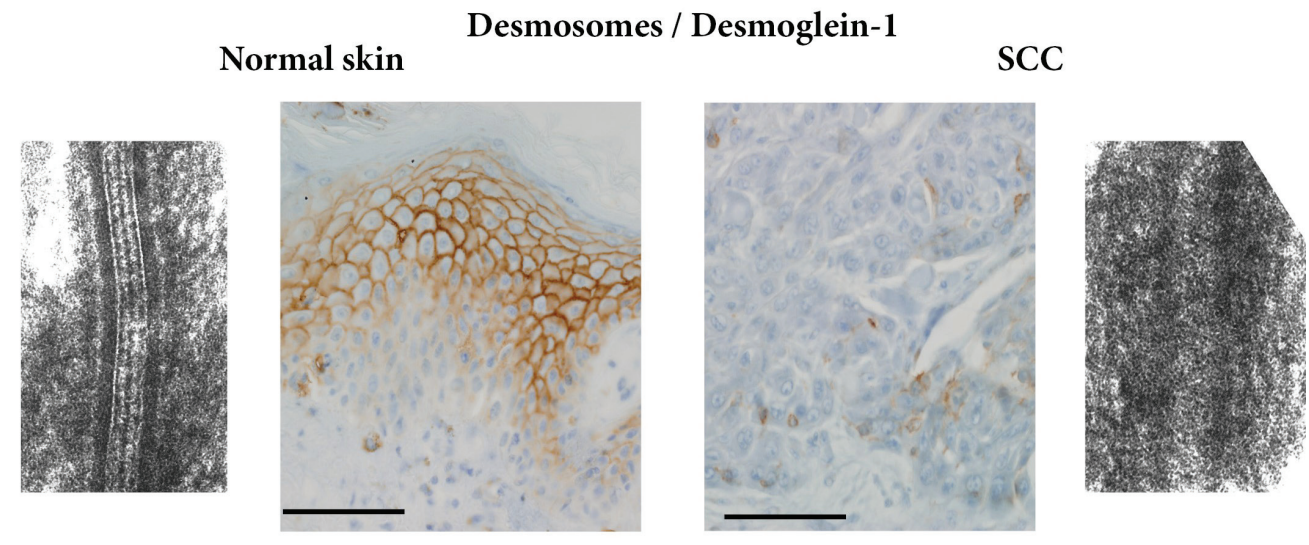

C Hemidesmosomes / Basal membrane

SCC

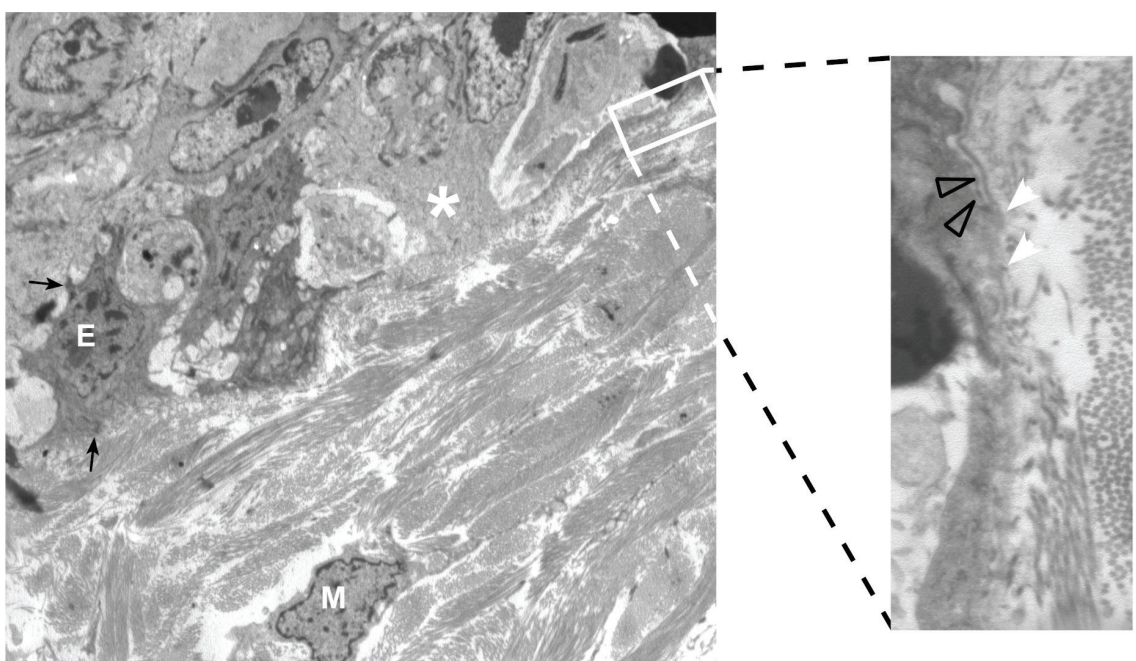

Figure 3: Ultrastructural study of invasive areas of SCC. A. Comparison of normal skin and invasive area of SCC shows a partial disappearance of zonula adherens, a fact confirmed by immunoperoxydase staining of claudin-1 (bar $=25 \mu \mathrm{m})$. B. Comparison of normal skin and invasive area of SCC shows a partial disappearance of desmosomes, a fact confirmed by immunoperoxydase staining of desmoglein-1 (bar $=25 \mu \mathrm{m})$. C. Epithelial cells (E) with remaining desmosomes (black arrows) and mesenchymal cells (M) in the dermis, are close to cells within the basal layer (white asterisk) with scarce junctions and basal membrane disappearance, possibly indicative of a lessening of the epithelial characteristics (X 4000). Higher magnification shows basal membrane disappearance (white arrow heads) which can be compared with preserved basal membrane areas (grey arrows heads) (X30000). 
and invasive areas. Combined laser-microdissection and molecular analyses enabled us to show that these donor-derived stem cells expressed higher levels of EMT markers than recipient stem cells.

We previously provided evidence for a donor epithelial cell contribution to the skin SCC in kidneytransplant recipients [5]. Here, to study whether stemcells were among the donor-derived cells that homed to the recipient skin SCC, we used the Y-chromosome as a marker for male donor cells in female recipients and CD133 as a stem-cell marker [6]. In the choice of CD133 as a stem cell marker, we took into account: i) the fact that the donor-derived cells were issued from a kidney transplant, because kidney stem cells express CD133 [7], and ii) the fact that numerous studies characterized CD133 as a human cancer stem cell marker [8-16], particularly in human primary skin SCC [17].

Using two independent methods, we identified for the first time donor-derived stem-cells in SCC of kidneytransplant recipients.

Their presence in concomitant AK suggests that the homing of stem-cells from the kidney transplant to the skin also occurred at a preneoplastic stage.

The absence of donor-derived stem-cells in the normal skin surrounding SCCs and AKs could be linked to the tissue remodelling accompanying disease progression since stem-cells are recruited to sites of experimental skin injuries [18], and tissue repair shares common mechanisms with stem-cell renewal in carcinogenesis [19].

These donor-derived stem-cells were more numerous in SCC than in AK, and preferentially situated in the outer basal layers corresponding to the invasive areas of SCC. Therefore we addressed the question of the participation of these donor-derived stem-cells in tumor progression in recipient skin SCC.

We first tested the proliferation using Ki67, abundantly expressed in epithelial cells of SCC invasive areas. However we did not find in these areas cells coexpressing CD133 and Ki67.

This is coherent with in vitro studies showing that cancer stem cells are not in a proliferative state [20,21].

We then tested if these donor-derived stem cells participated to tumor cell invasion. An important mechanism contributing to tumor cell invasion and migration is EMT $[22,23]$, characterized by concomitant loss of epithelial markers and acquisition of mesenchymal markers such as vimentin in tumor cells [24-26]. In vitro, the acquisition of vimentin increases tumor cell invasiveness [27]. EMT markers can also be co-expressed with CD133 in cancer stem-cells in metastatic epithelial cancer [28, 29]. Here we found CD133/vimentin coexpressing cells in SCC but not in AK.

To further characterize the EMT process in CD133 expressing cells in SCC, we laser-microdissected CD133/vimentin co-expressing cells, and compared their molecular markers with those of cells only expressing CD133 in the same SCC areas. CD133/ vimentin co-expressing cells had a higher level of the transcription factor SNAI1 (SNAIL1) and a lower level of CDH1 (E-cadherin), an adhesive molecule involved in keratinocyte junctions, together with claudin-1 for zonula adherens and desmoglein-1 for desmosomes [30]. Although these CD133/vimentin co- expressing cells were not numerous, a large percentage of them was found to be donor-derived. The fact that donor- derived stem-cells expressing vimentin were found in SCC but not in AK is an argument in favour of their invasive potential.

If, in this study performed in patients' skin samples, we could demonstrate the presence of donor-derived stem cells, and their expression of EMT markers, we could not perform in vitro and in vivo experiments to search for a clonal expansion of these cells. Given the limited numbers of donor-derived stem cells that we found, it is unlikely that these cells alone drove the tumor growth. Recent studies suggest that different types of cancer stem cells could participate in the same tumor [31]. The clinical situation of gender-mismatched kidney transplantation is particularly suitable to study the heterogeneity of cancer stem cells within tumors. We demonstrate here for the first time that part of cancer stem cells in recipient SCC is donor-derived. It cannot be excluded that the different types of cancer stem cells play different roles in tumor maintenance and progression.

In conclusion, the present in situ study, performed on human tumors, identified donor-derived stem-cells in recipient skin SCC. It also demonstrated the contribution of donor-derived stem-cells expressing EMT markers to invasive cells in recipient skin SCC.

\section{MATERIALS AND METHODS}

\section{Patients and samples}

From 1991 to 2012, four females with gendermismatched kidney-transplants and no earlier male pregnancy had SCC and AK samples remaining after the diagnosis had been established, and available recipient DNA. Patient 1, a female with membranous glomerulonephritis, had received a male kidney transplant at age 43, and treatment with azathioprine, corticosteroids, tacrolimus, mycophenolate-mofetil and cyclosporine. Patient 2, a female with a urinary malformation, had received a male kidney transplant at age 46 with the same immunosuppressive drugs. Patient 3, a female with membranous glomerulonephritis had received a male kidney transplant at age 18 with the same five drugs. Patient 4, a female with mesangial sclerosis, had received a male kidney transplant at age 24 with the same immunosuppression except for tacrolimus. The two other patients, two females with an earlier male pregnancy, 
were excluded from the chimerism study. The study was approved by Institutional Review Board of Hôpital SaintLouis (Paris, France) and informed consents were obtained according to the Helsinki Declaration.

All AK and SCC biopsy samples, taken for diagnostic purposes, had been formalin-fixed and paraffinembedded, another part was glutaraldehyde-fixed and embedded in epoxy resin.

$\mathrm{AK}$ and SCC were concomitant but not contiguous, and histological diagnoses were independently reviewed by two pathologists (AJ, LV).

\section{XY-FISH analysis}

It focused on the epidermal basal layers for AK, and on the epidermal basal layers and invasive areas for SCC. For XY-FISH analysis, $5 \mu \mathrm{m}$-thick sections were $\mathrm{HCl}$-treated for $15 \mathrm{~min}$, proteinase $\mathrm{K}$-digested for $20 \mathrm{~min}$ and formaldehyde-fixed. CEP X/Y-DNA probes (Vysis, Abbott-Molecular, Illinois, U.S.A) were denatured for 10 min at $90^{\circ} \mathrm{C}$, hybridized (Thermobrite, Abbot-Molecular) for 16 hours at $42^{\circ} \mathrm{C}$, and Vectashield-mounted (Vector Labs, Burlingam, U.S.A).Tissue sections were analysed by two pathologists (AJ, LV) on a motorized Z-axismicroscope (BX-61-Olympus, Tokyo, Japan), alternately using bright and epi-fluorescent light. Microscope images obtained through an UPlan-FI 100x/1.3NA objective were captured using Cell-F-software. For chromosomal analysis, 10 sequential Z-stack images of the same field were captured at $0.5 \mu \mathrm{m}$ intervals. $\mathrm{X}$ and $\mathrm{Y}$ signals were counted on 100 cells in each AK and each SCC, and also on 100 cells from non-tumoral surrounding tissue.

Two controls were used for FISH YX analyses: i) $\mathrm{AK}$ and SCC from one male patient with male kidney transplant, ii) AK and SCC from 2 male patients without kidney transplantation, to calculate a correction factor for XY-positive cells.

Combined XY-FISH and cytokeratin or CD133 immunostainings were performed on the same sections of AK and SCC using CEP X/Y DNA probes (Vysis), followed by staining with anti-human cytokeratin mouse antibody (clone AE1/AE3; Roche Diagnostics, Mannheim, Germany), and AMCA-conjugated anti-mouse IgG horse secondary antibody (Vector Laboratories, Peterborough, United Kingdom) or CD133 (clone AC133, Miltenyi Biotec Inc., Auburn, USA). Positive cells were counted on 500 cells in each AK and each SCC, and also on 500 cells from non-tumoral surrounding tissue.

\section{Immunostainings and laser-microdissection}

On the $7 \mu \mathrm{m}$-thick sections of AK and SCC, CD133 immunostainings were performed using an indirect immunoperoxidase method (Discovery/Roche) using monoclonal mouse anti-human CD133 antibody (clone
AC133 Miltenyi Biotec Inc., Auburn, USA) as the primary antibody. CD133/ vimentin double immunofluorescence labelling was performed on $\mathrm{AK}$ and SCC following paraffin sections using the same anti CD133 mouse monoclonal antibody and anti-human vimentin mouse monoclonal antibody (clone V9, Dako, Glostrup, Danemark) as primary antibodies. Since these two primary antibodies were mouse antibodies of IgG1 isotype, the anti CD133 antibody was bound to Alexa Fluor ${ }^{\circledR} 488$, and the anti-vimentin antibody to Alexa Fluor ${ }^{\circledR}$ 594, using ApexAlexa Fluor ${ }^{\circledR}$ kits (Invitrogen, France).

On the $7 \mu \mathrm{m}$-thick sections of SCC, Ki67, Snail/ Slug, immunostainings were performed using monoclonal mouse anti-human Ki67 antibody (clone MIB-1, Dako) and rabbit anti-human Snail/Slug polyclonal antibody (Sigma-Aldrich). Double CD133/Ki67 and CD133/ snail-slug immunofluorescence labelling were performed on SCC following paraffin sections using the same anti CD133 mouse monoclonal antibody and monoclonal mouse anti-human Ki67 antibody (clone MIB-1, Dako), and rabbit anti-human Snail/Slug (ab85936, Abcam, UK) as primary antibodies. Since these two primary antibodies were mouse antibodies of IgG1 isotype, the anti CD133 antibody was bound to Alexa Fluor ${ }^{\circledR} 488$, and the antiKi67 and anti -snail/slug antibodies to Alexa Fluor® 594, using Apex-Alexa Fluor ${ }^{\circledR}$ kits (Invitrogen, France). For all immunostainings, the controls were absence of primary antibody and incubation with an irrelevant antibody of the same isotype. Counts of CD133-expressing cells and of cells coexpressing CD133 and vimentin and of cells co-expressing CD133 and snail/slug were performed by two pathologists at magnification $\mathrm{x} 250$ on a minimum of 500 keratinocytes in the epidermal basal layers for $\mathrm{AK}$ and in the epidermal basal layers and invasive areas for SCC. Results were expressed as the mean percentage of positive cells.

After CD133 immunostainings in the epidermal basal layers of $\mathrm{AK}$ and in the epidermal basal layers and invasive areas of SCCs, a minimum of $50 \mathrm{CD} 133^{+}$cells and 100 CD133-cells were microdissected. After double CD133 and vimentin immunostainings a minimum of $50 \mathrm{CD} 133 /$ vimentin co-expressing cells and 50 cells only expressing CD133 were microdissected in the same areas. After double CD133 and snail/slug immunostainings, a minimum of 50 CD133/snail-slug co-expressing cells and 50 cells only exressing CD133 were microdissected in the epidermal basal layers and invasive areas of SCCs. A minimum of 100 normal keratinocytes were microdissected from surrounding areas of SCCs. Laser-microdissection was performed using a PALM-Microbeam/Zeiss system with a pulsed UV-A nitrogen laser $(337 \mathrm{~nm})$ to select cell populations after immunostaining. For each cell population, two laser-microdissections were performed to extract: i) DNA using Qiagen-kit (Qiagen/Courtaboeuf/France), ii) total RNA using Qiagen-kit (Qiagen/Courtaboeuf/France) 
and reverse-transcription using random primers with SuperScriptTM II Reverse Transcriptase (Invitrogen).

\section{Droplet digital PCR assay}

ddPCR enabled us to check the specificity of laser-microdissected cell populations using CD133 ( Hs01009250 m1 (NM 001145847)), CD45 (Hs00365634_g1 (NM 002838.3)), and vimentin ((Hs00185584_m1 (NM_003380.3)). Human TBP assay was used as a housekeeping gene (Hs99999910_m1, NM_003194.4).

To detect the number of cells with the Y-chromosome in CD133 expressing cells, a minimum of 50 laser-microdissected cells were studied in three selected populations: CD133/vimentin or CD133/snailslug co-expressing cells, and cells only expressing CD133. The primers and probes were designed to target the ZFY sequences (Applied Biosystems Hs05705529_cn), using RNase $\mathrm{P}$ as a reference gene (Applied Biosystems 4401631). It contained specific forward and reverse primers, FAM dye-labelled ZFY probes and VIC labelled RNase $\mathrm{P}$ probes. The percentage of Y-bearing cells was determined as the ZFY / RNase P ratio.

For CDH1 and SNAI1 gene expression analyses, digital droplet PCR assays were performed using Hs01023894_m1 (NM_004360.3) and Hs00195591_m1 (NM_005985.3) primers (Applied Biosystems).

Droplet digital PCR assays were performed in triplicate. Controls were no template, male, and female DNA. Reaction mixes were prepared using standard Taqman primer/probe chemistry with a $2 \mathrm{X}$ ddPCR Mastermix (BioRad, Laboratories, CA), a $20 \mathrm{X}$ primer/ probe $(900 / 250 \mathrm{nM})$, and $5 \mu 1$ sample DNA template in a final volume of $20 \mu$ l.

The PCR products were analysed using QuantaSoft software (BioRad Laboratories, CA). Raw data were collected on the Bio-Rad QX100 instrument.

CD133, CD45, CDH1 and SNAI1 mRNA expressions were expressed as the copy number of each gene / TBP copy number ratio.

\section{Ultrastructural study and epidermal junction immunostainings}

For electron microscopy, skin biopsies were fixed in $2 \%$ glutaraldehyde-buffered $0.1 \mathrm{M}$. cacodylate and embedded in epoxy resin. Ultrathin sections were stained with uranyl acetate and lead citrate. Analysis, performed on a Hitachi-7650, focused on cells and basal membranes of invasive areas of SCC.

We looked for epithelial cell characteristics such as junctions (zonula adherens, desmosomes and hemidesmosomes since epithelial cells are keratinocytes in SCC) and for mesenchymal characteristics (no junction of any type, numerous filaments within the cytoplasm extruding from the cytoplasm). On basal membranes, we looked for changes such as thinning or thickening, disappearance of the lamina densa, lamina lucida, or hemidesmosomes.

Claudin-1 and desmoglein-1 immunostainings were performed using an indirect immunoperoxidase method (Discovery/Roche) on $5 \mu \mathrm{m}$-thick sections of SCC and on normal skin using polyclonal rabbit anti-human anticlaudin-1 antibody (Sigma-Aldrich) and anti-DSG1 (Sigma-Aldrich) as the primary antibodies

\section{ACKNOWLEDGMENTS}

funding from University Paris 7, Inserm, INCA and Région Ile-de France and Société Française de Dermatologie ; the authors are grateful to S. LeclercMercier for sharing her expertise in keratinocyte junctions, and to Mrs Angela Swaine for reviewing the English language

\section{CONFLICTS OF INTEREST}

The authors state no conflict of interest

\section{REFERENCES}

1. Lott DG, Manz R, Koch C and Lorenz RR. Aggressive behavior of nonmelanotic skin cancers in solid organ transplant recipients. Transplantation. 2010; 90:683-687.

2. Walsh SB, Xu J, Xu H, Kurundkar AR, Maheshwari A, Grizzle WE, Timares L, Huang CC, Kopelovich L, Elmets $\mathrm{CA}$ and Athar M. Cyclosporine a mediates pathogenesis of aggressive cutaneous squamous cell carcinoma by augmenting epithelial-mesenchymal transition: role of TGFbeta signaling pathway. Molecular carcinogenesis. 2011; 50:516-527.

3. De Craene B, Denecker G, Vermassen P, Taminau J, Mauch C, Derore A, Jonkers J, Fuchs E and Berx G. Epidermal Snail expression drives skin cancer initiation and progression through enhanced cytoprotection, epidermal stem/progenitor cell expansion and enhanced metastatic potential. Cell death and differentiation. 2014; 21:310-320.

4. Verneuil L, Varna M, Leboeuf C, Plassa LF, Elbouchtaoui M, Loisel-Ferreira I, Bouhidel F, Peraldi MN, Lebbe C, Ratajczak P and Janin A. Donor-derived keratinocytes in actinic keratosis and squamous cell carcinoma in patients with kidney transplant. The Journal of investigative dermatology. 2013; 133:1108-1111.

5. Verneuil L, Varna M, Ratajczak P, Leboeuf C, Plassa LF, Elbouchtaoui M, Schneider P, Sandid W, Lebbe C, Peraldi MN, Sigaux F, de The H and Janin A. Human skin carcinoma arising from kidney transplant-derived tumor cells. The Journal of clinical investigation. 2013; 123:37973801 . 
6. Li Z. CD133: a stem cell biomarker and beyond. Experimental hematology \& oncology. 2013; 2:17.

7. Bussolati B, Bruno S, Grange C, Buttiglieri S, Deregibus MC, Cantino D and Camussi G. Isolation of renal progenitor cells from adult human kidney. The American journal of pathology. 2005; 166:545-555.

8. Eramo A, Lotti F, Sette G, Pilozzi E, Biffoni M, Di Virgilio A, Conticello C, Ruco L, Peschle C and De Maria R. Identification and expansion of the tumorigenic lung cancer stem cell population. Cell death and differentiation. 2008; 15:504-514.

9. Fang DD, Kim YJ, Lee CN, Aggarwal S, McKinnon K, Mesmer D, Norton J, Birse CE, He T, Ruben SM and Moore PA. Expansion of CD133(+) colon cancer cultures retaining stem cell properties to enable cancer stem cell target discovery. British journal of cancer. 2010; 102:12651275.

10. Kusumbe AP, Mali AM and Bapat SA. CD133-expressing stem cells associated with ovarian metastases establish an endothelial hierarchy and contribute to tumor vasculature. Stem Cells. 2009; 27:498-508.

11. Ma S, Chan KW, Hu L, Lee TK, Wo JY, Ng IO, Zheng $\mathrm{BJ}$ and Guan XY. Identification and characterization of tumorigenic liver cancer stem/progenitor cells. Gastroenterology. 2007; 132:2542-2556.

12. Maeda S, Shinchi H, Kurahara H, Mataki Y, Maemura K, Sato M, Natsugoe S, Aikou T and Takao S. CD133 expression is correlated with lymph node metastasis and vascular endothelial growth factor-C expression in pancreatic cancer. British journal of cancer. 2008; 98:13891397.

13. Shi CJ, Gao J, Wang M, Wang X, Tian R, Zhu F, Shen M and Qin RY. CD133(+) gallbladder carcinoma cells exhibit self-renewal ability and tumorigenicity. World journal of gastroenterology : WJG. 2011; 17:2965-2971.

14. Tabu K, Sasai K, Kimura T, Wang L, Aoyanagi E, Kohsaka S, Tanino M, Nishihara $\mathrm{H}$ and Tanaka S. Promoter hypomethylation regulates CD133 expression in human gliomas. Cell research. 2008; 18:1037-1046.

15. Xiao Y, Ye Y, Yearsley K, Jones S and Barsky SH. The lymphovascular embolus of inflammatory breast cancer expresses a stem cell-like phenotype. The American journal of pathology. 2008; 173:561-574.

16. Yanagisawa S, Kadouchi I, Yokomori K, Hirose M, Hakozaki M, Hojo H, Maeda K, Kobayashi E and Murakami T. Identification and metastatic potential of tumor-initiating cells in malignant rhabdoid tumor of the kidney. Clinical cancer research : an official journal of the American Association for Cancer Research. 2009; 15:30143022.

17. Patel GK, Yee CL, Terunuma A, Telford WG, Voong N, Yuspa SH and Vogel JC. Identification and characterization of tumor-initiating cells in human primary cutaneous squamous cell carcinoma. The Journal of investigative dermatology. 2012; 132:401-409.

18. Zong ZW, Cheng TM, Su YP, Ran XZ, Shen Y, Li N, Ai GP, Dong SW and Xu H. Recruitment of transplanted dermal multipotent stem cells to sites of injury in rats with combined radiation and wound injury by interaction of SDF-1 and CXCR4. Radiat Res. 2008; 170:444-450.

19. Beachy PA, Karhadkar SS and Berman DM. Tissue repair and stem cell renewal in carcinogenesis. Nature. 2004; 432:324-331.

20. Liu S, Patel SH, Ginestier C, Ibarra I, Martin-Trevino R, Bai S, McDermott SP, Shang L, Ke J, Ou SJ, Heath A, Zhang KJ, Korkaya H, Clouthier SG, Charafe-Jauffret E, Birnbaum D, et al. MicroRNA93 regulates proliferation and differentiation of normal and malignant breast stem cells. PLoS Genet. 8:e1002751.

21. Kleffel S and Schatton T. Tumor dormancy and cancer stem cells: two sides of the same coin? Advances in experimental medicine and biology. 2013; 734:145-179.

22. Coghlin C and Murray GI. Current and emerging concepts in tumour metastasis. J Pathol. 2010; 222:1-15.

23. Kalluri $\mathrm{R}$ and Weinberg RA. The basics of epithelialmesenchymal transition. The Journal of clinical investigation. 2009; 119:1420-1428.

24. Mandal M, Myers JN, Lippman SM, Johnson FM, Williams MD, Rayala S, Ohshiro K, Rosenthal DI, Weber RS, Gallick GE and El-Naggar AK. Epithelial to mesenchymal transition in head and neck squamous carcinoma: association of Src activation with E-cadherin down-regulation, vimentin expression, and aggressive tumor features. Cancer. 2008; 112:2088-2100.

25. Paccione RJ, Miyazaki H, Patel V, Waseem A, Gutkind JS, Zehner ZE and Yeudall WA. Keratin down-regulation in vimentin-positive cancer cells is reversible by vimentin RNA interference, which inhibits growth and motility. Molecular cancer therapeutics. 2008; 7:2894-2903.

26. Scanlon CS, Van Tubergen EA, Inglehart RC and D'Silva NJ. Biomarkers of epithelial-mesenchymal transition in squamous cell carcinoma. Journal of dental research. 2013; 92:114-121.

27. Burch TC, Watson MT and Nyalwidhe JO. Variable metastatic potentials correlate with differential plectin and vimentin expression in syngeneic androgen independent prostate cancer cells. PLoS One. 2013; 8:e65005.

28. Asli NS and Harvey RP. Epithelial to mesenchymal transition as a portal to stem cell characters embedded in gene networks. BioEssays : news and reviews in molecular, cellular and developmental biology. 2013; 35:191-200.

29. Chen C, Zimmermann M, Tinhofer I, Kaufmann AM and Albers AE. Epithelial-to-mesenchymal transition and cancer stem(-like) cells in head and neck squamous cell carcinoma. Cancer Lett. 2013; 338:47-56.

30. Niessen CM. Tight junctions/adherens junctions: basic structure and function. The Journal of investigative dermatology. 2007; 127:2525-2532. 
31. Piccirillo SG, Combi R, Cajola L, Patrizi A, Redaelli S, Bentivegna A, Baronchelli S, Maira G, Pollo B, Mangiola A, DiMeco F, Dalpra L and Vescovi AL. Distinct pools of cancer stem-like cells coexist within human glioblastomas and display different tumorigenicity and independent genomic evolution. Oncogene. 2009; 28:1807-1811. 